\title{
Self-Perceived Competence and Learning Barriers of Medical Students in Family and Community Medicine Clerkship During COVID-19 Pandemic
}

\author{
Witri Pratiwi ${ }^{1}$, Tissa Octavira ${ }^{2}$ and Ouve Rahadiani Permana ${ }^{3}$ \\ ${ }^{1}$ Department of Community Medicine and Public Health, Faculty of Medicine, Universitas Swadaya Gunung Jati, \\ Indonesia \\ ${ }^{2}$ Department of Medical Education, Faculty of Medicine, Universitas Swadaya Gunung Jati, Indonesia \\ ${ }^{3}$ Department of Bioethics, Faculty of Medicine, Universitas Swadaya Gunung Jati, Indonesia
}

*Corresponding author. Email: we3.borneo@gmail.com

\begin{abstract}
Medical studies during the COVID-19 pandemic faced several obstacles that may affect students' self-perceived competence. Objectives: This study aims to determine students' self-perceived competence in family and community medicine clerkships and learning barriers faced during the COVID-19 pandemic. Methods: A cross sectional study was conducted on medical students of Medical Faculty Universitas Swadaya Gunung Jati Indonesia who underwent family and community medicine clerkships during COVID-19 pandemic. Data were collected through a validated questionnaire to determine self-perceived competence in the area of competency: Managing health problems. The core competency was broken down into 6 competency components based on Indonesian Doctor Competency Standards (SKDI-2012). The questionnaire also contains questions about the most memorable activities and learning barriers faced by the students. Results: There were 49 students who participated in this study, consisting of $28.6 \%$ male and $71.4 \%$ female. There were no students who have low self-perceived competence in all competency components. Several learning barriers were identified, whether related to COVID-19 or not. Internet connection is the main obstacle when learning online $(63.3 \%)$. The limitation of health services (49\%) and the risk of being infected with COVID-19 (44.4\%) were the major learning barriers in public health services. Language differences (30.6\%) and limited types of drugs at public health centre (12.2\%) were also faced by students. Conclusions: Medical students in family and community medicine clerkship have moderate and high self-perceived competencies even though they face several learning barriers. However, actions are needed to minimize the learning barriers.
\end{abstract}

Keywords: COVID-19, clerkship, public health.

\section{INTRODUCTION}

Medical education aims to educate professional doctors through a standardized process according to the needs of public health services.[1] In primary care settings, general practitioners play important role so they have to master competencies in the field of public health.[2] The family and community medicine clerkship is a final rotation in the professional stage of medical education at the Faculty of Medicine, Universitas Swadaya Gunung Jati, Indonesia. It is carried out at the public health center (Puskesmas) with learning objectives according to the competencies listed in the Indonesian Doctor Competency Standards (SKDI), especially the community management competency area. Medical students are expected to be able to manage health problems in a comprehensive, holistic, integrated and sustainable manner in the context of primary health care.[1]

One of the important competency assessments is through self-perception (self-assessment) of competence after students complete the learning process. Through selfperception of competence, we can find out how much students master a competency based on their own assessment.[3] Based on previous studies, students who have good self-perception of competence will have good internal motivation so they do not easily give up to become better and master. On the other hand, less self- 
perception of competence is related to lack of persistence and performance goals.[4], [5]

The medical education system during the COVID-19 pandemic faced challenges and obstacles that might affect the self-perception of competence of medical students.[3], [6] This study aims to identify medical students' self-perception of competencies achievement in family and community medicine clerkship and the learning barriers during the COVID-19 pandemic.

\section{METHODS}

\section{A. Study design and participants}

This research is a descriptive observational study conducted at Faculty of Medicine, Universitas Swadaya Gunung Jati, Indonesia. Data collection was carried out in September 2020. An online questionnaire was given to 55 medical students who had completed family and community medicine clerkship for 12 weeks. They were the first group of medical students who underwent family and community medicine clerkship during COVID-19 pandemic. A total of 49 students agreed to participate in this study and filled out the questionnaire completely $(89,1 \%$ response rate).

\section{B. Data collection}

The questions on the questionnaire were arranged based on the learning objectives at family and community medicine clerkship of Faculty of Medicine, Universitas Swadaya Gunung Jati. The questionnaire that had been tested for validity and reliability consisted of 27 questions regarding perceptions of competence and several open-ended questions regarding the most memorable activities and obstacles faced by students.

The main competency areas were divided into 6 competency components based on SKDI which are:[1]

$\mathrm{C} 1$ : Conducting health promotion to individuals, families and communities

C2: Implementing prevention and early detection of health problems in individuals, families and communities;
C3: Managing individual, family and community health problems;

C4: Empowering and collaborating with community to improve health status;

C5: Managing resources effectively, efficiently and sustainably in solving health problems;

C6: Accessing, analyzing and implementing specific health policies based on the priority of each region in Indonesia.

The subjects were asked about their perceptions of competence on a 5-point Likert scale (strongly disagree, diagree, undecided, agree and strongly agree).

\section{Data analysis}

The data were processed using SPSS version 26. The total score of answers from each competency components was categorized into low self-perceived competence ( $<50 \%$ of the maximum possible score), moderate selfperceived competence (50-75\% of the maximum possible score) and high self-perceived competence (>75\% of the total possible maximum score). The data are presented descriptively using tables and graphs including mean, standard deviation, frequency distribution and percentage.

\section{RESULTS}

A total of 49 samples participated in this study consisted of $28.6 \%$ male and $71.4 \%$ female, aged $23-24$ years. Majority of the samples $(97.96 \%)$ have studied in medical faculty for 6 years (since 2014) and only 1 sample for 7 years (since 2013).

\section{A. Self-perceived competence}

Based on the research results, there were no students who had low self-perceived competence in all competency components. Most of the students had moderate selfperceived competence at $\mathrm{C} 1(57.1 \%), \mathrm{C} 2(85.7 \%), \mathrm{C} 4$ $(71.4 \%), \mathrm{C} 5(85.7 \%)$ and C6 $(85.7 \%)$. Whereas at C3, moderate and high self-perceived competence was almost the same, namely $49 \%$ and $51 \%$, respectively. High self-perception had the smallest percentage at $\mathrm{C} 2$, C5 and C6, namely $14.3 \%$. (Table 1)

Table 1. Self-perceived competence among medical students $(\mathrm{N}=49)$

\begin{tabular}{llccccc}
\hline Component of Competency & $\begin{array}{c}\text { Possible } \\
\text { score }\end{array}$ & Mean $( \pm$ SD) & $\begin{array}{c}\text { Low self- } \\
\text { perceived } \\
\text { competence } \\
\mathbf{n}(\%)\end{array}$ & $\begin{array}{c}\text { Moderate } \\
\text { self- } \\
\text { perceived } \\
\text { competence } \\
\mathbf{n}(\%)\end{array}$ & $\begin{array}{c}\text { High self- } \\
\text { perceived } \\
\text { competenc } \\
\text { e }\end{array}$ \\
\hline $\mathrm{C} 1 \quad \begin{array}{l}\text { Conducting health promotion to } \\
\text { individuals, families and } \\
\text { communities }\end{array}$ & $3-15$ & $12.63( \pm 0.929)$ & 0 & $28(57.1)$ & $21(42.9)$ \\
\hline
\end{tabular}




\begin{tabular}{lllllll}
\hline C2 & $\begin{array}{l}\text { Implementing prevention and } \\
\text { early detection of health } \\
\text { problems in individuals, } \\
\text { families and communities }\end{array}$ & $3-15$ & $11.94( \pm 1.088)$ & 0 & $42(85.7)$ & $7(14.3)$ \\
\hline C3 & $\begin{array}{l}\text { Managing individual, family } \\
\text { and community health problems }\end{array}$ & $15-75$ & $62.04( \pm 4.933)$ & 0 & $24(49)$ & $25(51)$ \\
\hline C4 & $\begin{array}{l}\text { Empowering and collaborating } \\
\text { with the community to improve } \\
\text { health status (C4) }\end{array}$ & $2-10$ & $8.33( \pm 0.875)$ & 0 & $35(71.4)$ & $14(28.6)$ \\
\hline C5 & $\begin{array}{l}\text { Managing resources effectively, } \\
\text { efficiently and sustainably in } \\
\text { solving health problems }\end{array}$ & $2-10$ & $8.00( \pm 0.842$ & 0 & $42(85.7)$ & $7(14.3)$ \\
\hline C6 & $\begin{array}{l}\text { Accessing, analyzing and } \\
\text { implementing specific health } \\
\text { policies based on the priority of } \\
\text { each region in Indonesia }\end{array}$ & $2-10$ & $7.78( \pm 1.159)$ & 0 & $42(85.7)$ & $7(14.3)$ \\
\hline
\end{tabular}

\section{B. Learning barriers}

The family and community medicine clerkship was conducted online for 2 weeks and offline at the Puskesmas for 10 weeks during COVID-19 pandemic. In online learning, students were divided into small groups (4-5 students) and given scenarios about a health problem. They conducted literature searches, critical appraisal to get references and discussions together with a tutor. The learning process was carried out using an online meeting application. Furthermore, students were asked to make health promotion media (poster or video) about the health problems discussed and shared it to their own social media accounts.

In offline learning at the Puskesmas, students participated in health services both inside the building (polyclinic, pharmacy, laboratory) and outside activities such as posyandu, posbindu. They also conducted home visits, health promotion and other health programs, such as immunization. The students also analyzed the health problems faced by the community in the working area of the Puskesmas, set priority problems, analyzed the causes of problems, developed alternative solutions to problems, determined and implemented problem solving efforts. Furthermore, they monitored and evaluated the problem solving efforts that had been carried out.

In this study, we identified several learning barriers faced by students. In online learning, the main learning barrier was poor internet connection (63.3\%). There were $36.7 \%$ of students facing problems regarding the learning environment when learning online. (Table 2)
The learning barriers that were faced by students at the Puskesmas were related to COVID-19 and not. Learning barriers related to COVID-19 included limited contact and communication with patients, the risk of COVID-19 infection, discomfort using personal protective equipment (PPE) and limitation of health services during the COVID-19 pandemic. The limitation of health services $(49 \%)$ and the risk of being infected with COVID-19 (44.4\%) were the major learning barriers in Puskesmas. Learning barriers that were not related to COVID-19 included language differences (30.6\%) and limited types of drugs at Puskesmas (12.2\%). (Table 2)

Table 2. Learning barriers of medical students $(\mathrm{N}=49)$

\begin{tabular}{lcc}
\hline Barriers based on learning setting & n & \% \\
\hline Online & & \\
$\quad$ Internet connection & 31 & 63.3 \\
$\quad$ Learning environment & 18 & 36.7 \\
\hline Public health center & & \\
$\quad$ Limited contact and communication & 12 & 24.5 \\
with patients & & \\
Risk of COVID-19 infection & 22 & 44.9 \\
Discomfort using PPE & 3 & 6.1 \\
Limitation of health services & 24 & 49 \\
Language differences & 15 & 30.6 \\
Limited types of drugs at Puskesmas & 6 & 12.2 \\
\hline
\end{tabular}

\section{Memorable activities}

There were several activities that impressed the students the most, including providing health services, home visits, health promotion, immunization programs and community diagnosis. Health service activities were the most memorable for most students (45\%). (Figure 1) 


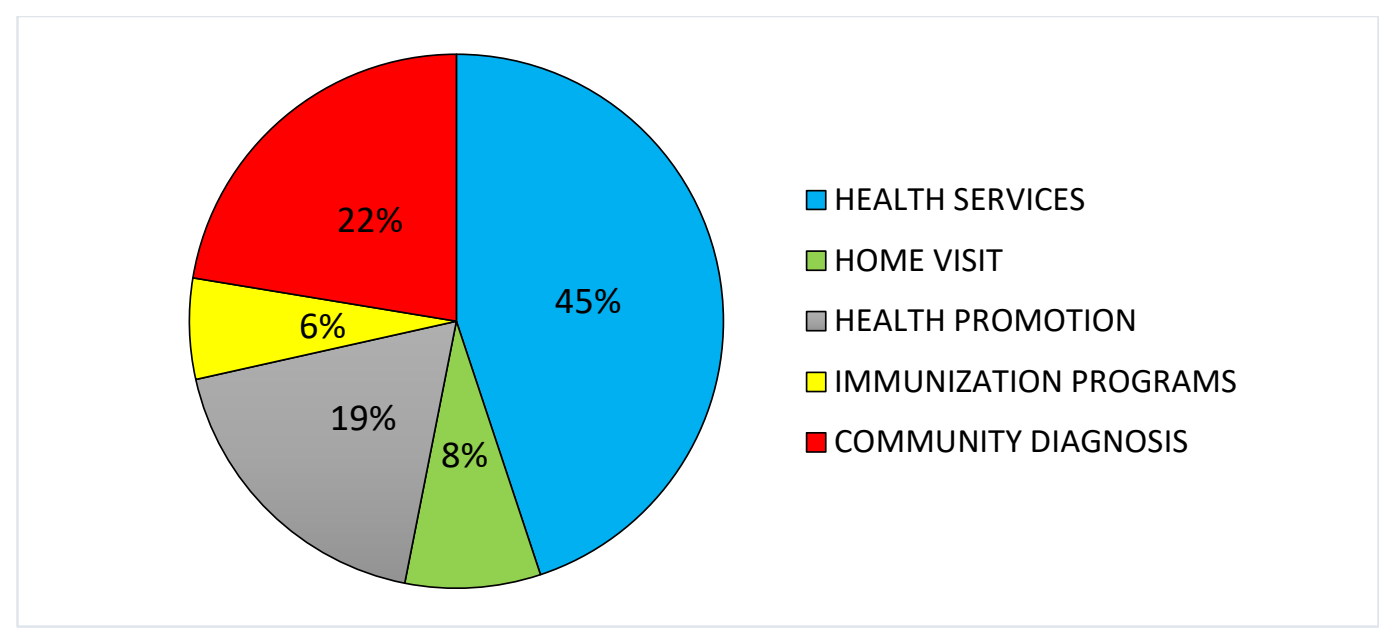

Figure 1. The most memorable activities during family and community medicine clerkship

\section{DISCUSSION}

Self-perceived competence is defined as a personal characteristic that reflects one's global expectation or belief in his/her ability to accomplish tasks. In this article, self-perceived competence is operationally defined as ability to perform competencies in family and community medicine clerkship. The results have shown that no students with low self-perceived competence in all competency components. Most of the students had moderate self-perceived competence in $\mathrm{C} 1, \mathrm{C} 2, \mathrm{C} 4, \mathrm{C} 5$, and C6. The number of students who had moderate and high self-perceived competence in $\mathrm{C} 3$ were almost the same. These results interestingly showed that the medical students studied well and achieved what they expected despite some learning barriers. However, this study did not analyze the factors related to the students' selfperceived competence.

Based on previous research, there were several factors that influenced good self-perceived competence, including the role of clinical supervisors who could facilitate students to learn well, provided feedback and motivation so the learning objectives could be achieved.[7] The role of effective clinical supervisors might enable students to overcome learning barriers, especially the less supportive and limited learning environment during the COVID-19 pandemic.

But other study results found that perception of teachers (clinical supervisors) and learning environment were not strongly correlated with self-perceived competence over a range of clinical, practical and personal skills. There are several other factors that influence self-perceived competence. One of them is the previous knowledges, skills and learning experiences.[7] The family and community medicine clerkship is the last rotation at the clerkship stage. Previously, students had learned many theories, clinical skills and other knowledge for 6 years, both in the undergraduates stage and in previous clinical rotations. They have also gained a lot of experiences in interacting with patients, determining comprehensive patient management and working as a team. In the field of public health, they have previously received theories and undertaken field practices at primary health care since the second year of the undergraduates stage. These make them more confident in their abilities and increase self-perceived competence.

The results of this study are in accordance with the research conducted by Lai, et al. that final year students have better understanding of their own abilities in relation to the curriculum, purpose in learning, good maturity and coping abilities. They are also more independent and apply self-directed learning so less dependent on teachers.[7]

Based on some previous studies, it was known that the main determinant of students' self-confidence and selfperceived competence was internal motivation.[7], [8] The study conducted by Kusurkar, et al. found that motivation was an independent variable that controls other variables. Motivation can come from external or internal. By having good motivation, students will have good learning and study behavior so that they can achieve academic success and good performance.[8], [9]

According to the cognitive evaluation theory, a subtheory within Self-Determination Theory, the level of autonomous academic motivation is dependent on one's perception of academic competence and selfdetermination. When university students do not feel competent in their study, their academic motivation will decrease, whereas when they perceive themselves with a high level of academic competence, their academic motivation is maintained or even enhanced.[10] 
This study results also found the small percentage of high self-perceived competence in C2, C5 and C6. These competencies require the role of other factors to be achieved properly, for example the availability of primary health care resources, regulation due to health care and management, as well as the participation of the community. These factors may be effect the students' self-perception of those competencies.

Despite the subjectivity associated with self-perception in determining performance, self-assessment has two important functions both as a mechanism for identifying one's weaknesses and strengths. Each of these mechanisms having distinct and complementary functions. As a mechanism for identifying weaknesses or gaps in one's skills and abilities, self-assessment serves several potential functions. Firstly, in daily practice, the identification of one's weaknesses allows the professional to self-limit in areas of limited competence. For example, in some circumstances the professional can quickly reject certain assignments because they are able to recognize that they are unlikely to complete the tasks. In other circumstances, an individual can realize that the task is beyond his ability, and can decide to consult or refer the problem to another individual. The ability to recognize tasks beyond one's competence is critical especially in the medical field where trial and error has no room as practitioners deal with people's lives.[11]

Online learning is an alternative solution for medical student education during the COVID-19 pandemic. It allows students to attend educational sessions face to face in real time from their own location, thereby minimizing the risk of COVID-19 transmission.[6] In addition, online learning also allows students to get wider and more diverse information. But in practice, online learning certainly faces several barriers.[12]

There are 4 categories of learning barriers in online learning during the COVID-19 pandemic, namely technological, individual, domestic, institutional and community barriers.[13] Based on this study results, learning barriers faced by medical students were internet connection and learning environment. It is in line with some previous studies that poor internet connection is one of the most common technological barriers faced by medical students while studying online during the COVID-19 pandemic.[13], [14] This barrier is not only faced by medical students in Indonesia but also in several countries, especially countries with less internet infrastructure.[6], [13] Unsupportive learning environments, such as noisy backgrounds, family distraction, small and uncomfortable places are domestic barriers that are often faced by medical students when learning online during COVID-19 pandemic. Students compare their previous learning experience with the online learning they are currently taking. Previously, learning was carried out in comfortable and quiet classrooms, while online learning was carried out in individual places where it was difficult to control a conducive learning environment.[13], [14]
The limitation of Puskesmas services was identified as the main learning barrier faced by medical students while studying at the Puskesmas. During the COVID-19 pandemic, some services were limited or temporarily suspended.[15] It may cause students to feel less opportunity to meet patients or participate in programs that are usually routinely carried out. Health promotion that gathered large numbers of people was also eliminated.

Some medical students also feel worried about contracting COVID-19 during their activities. In the Puskesmas, they met directly with many patients and the community so that the risk of contracting COVID-19 increases. Actually, before starting clerkship activities, medical students have been given training on COVID-19 prevention procedures. But feelings of worry and fear are naturally felt because of the high number of health workers in Indonesia who have contracted and even died due to COVID-19. Based on data until January 2021, the number of medical and health workers in Indonesia who died from COVID-19 was 647 people and it was the highest in Asia.[16] Based on previous research, it is also known that the COVID-19 pandemic causes psychological pressure and even mental illness in health workers.[17], [18] Monitoring the psychological state of students and providing periodic motivation may be needed so that they can carry out activities optimally.

Another learning barrier faced by students was limited contact and communication with patients. Before the pandemic, doctor-patient contact was carried out directly so that doctor-patient contact and communication could be optimal. During the COVID-19 pandemic, consultation time for each patient was limited and there was a transparent barrier between doctors and patients.[15] The use of PPE also make it impossible to maintain eye contact with patients.[19] In addition, the use of PPE is also uncomfortable due to heat stress and limits movement for its users.[20] However, everything is done to ensure the safety of health workers from contracting COVID-19.

Another not related to COVID-19 learning barrier is language differences. Some of the patients used to communicate in their local language which the students from other areas do not understand it. Though understanding patients language is very important to prevent miscommunication and support effective doctorpatient communication.[21] Students need to learn local community language, especially the language commonly used by the local community regarding complaints of several diseases before undergoing family and community medicine clerkship.

The limited types of drugs in the Puskesmas are also a learning barrier for students. The medicines they learn in the textbooks are sometimes not available at the Puskesmas. It makes students need to adjust therapy according to the available drugs. But on other side, this 
situation was a good opportunity for students to learn in utilizing existing resources to provide health services even though they are limited in resources.

The identified learning barriers did not seem to really influence their self-perceived competence. It is indicated by the activities that makes them memorable and provide a pleasant experience when learning so that the limitations of the learning environment do not become an obstacle. This study results identified some activities during the family and community medicine clerkship that were very memorable for students, such as providing health services, home visits, health promotion, immunization programs and community diagnosis. The learning location in primary care may provide the different experiences compare to previous clerkship rotations performed in the hospital. Primary care services prioritize preventive and promotive aspects rather than curative services that they usually do in hospitals.[20] At the Puskesmas, they may find patients with complaints different from those they found in the hospital. They also can participate directly in community-based activities and explore public health problems in a more holistic and comprehensive manner.

\section{STUDY LIMITATION}

This study was conducted when the family and community medicine clerkship was restarted after being temporarily suspended due to the COVID-19 pandemic. So the small number of the samples is one of these study limitations. In addition, self-perceived competence is a personal assessment so there are subjective sides that differ from one individual to another. This study also did not analyze the factors that affect self-perceived competence of medical students. Research on this matter needs to be done further.

\section{CONCLUSION}

Medical students in family and community medicine clerkship have moderate and high self-perceived competencies even though they face several learning barriers. Students also experience activities that impress them even though they face several obstacles. Some actions to overcome or minimize learning barriers are needed so that medical students can undergo family and community medicine clerkship more optimally.

\section{AUTHORS' CONTRIBUTIONS}

Research ideas were compiled by all research members (WP, TO and ORP). WP as the main researcher in this research conducted questionnaire development, data collection, analysis and interpretation of research data. The research design was prepared by WP and TO. The preparation of manuscripts was carried out by WP, TO and ORP.
All research members have full access to the research data and are fully responsible for the accuracy of the research data.

\section{ACKNOWLEDGMENTS}

We express our deepest gratitude to respondents who have been willing to participate in this research. We would also like to thank our beloved institution: Universitas Swadaya Gunung Jati for always giving us great support.

\section{REFERENCES}

[1] Indonesian Medical Council, Standar kompetensi dokter Indonesia Konsil Kedokteran Indonesia, 2nd ed. Jakarta, 2012.

[2] S. Leeder, S. Corbett, and T. Usherwood, "General practice registrar education beyond the practice: The public health role of general practitioners," Aust. Fam. Physician, vol. 45, no. 5, pp. 266-269, 2016.

[3] S. Yeo and B. H. Chang, "Students' selfassessment of achievement of terminal competency and 4-year trend of student evaluation on outcome-based education," Korean J. Med. Educ., vol. 31, no. 1, pp. 39-50, 2019.

[4] T. J. Ten Cate, R. A. Kusurkar, and G. C. Williams, "How self-determination theory can assist our understanding of the teaching and learning processes in medical education. AMEE Guide No. 59," Med. Teach., vol. 33, no. 12, pp. 961-973, 2011.

[5] J. Ferla, M. Valcke, and G. Schuyten, "Judgments of self-perceived academic competence and their differential impact on students' achievement motivation, learning approach, and academic performance," Eur. J. Psychol. Educ., vol. 25, no. 4, pp. 519-536, 2010.

[6] A. Al Samaraee, "The impact of the COVID-19 pandemic on medical education," Br. J. Hosp. Med., vol. 81, no. 7, pp. 1-4, 2020.

[7] N. M. Lai, S. Nalliah, R. C. Jutti, Y. Y. Hla, and V. K. E. Lim, "The educational environment and self-perceived clinical competence of senior medical students in a Malaysian medical school," Educ. Heal. Chang. Learn. Pract., vol. 22, no. 2, pp. 1-15, 2009.

[8] R. A. Kusurkar, T. J. Ten Cate, M. Van Asperen, and G. Croiset, "Motivation as an 
independent and a dependent variable in medical education: A review of the literature," Med. Teach., vol. 33, no. 5, pp. 142-159, 2011.

[9] R. A. Kusurkar, Motivation in Medical Students, no. March 2012. 2012.

[10] E. S. C. Liu, C. J. Ye, and D. Y. Yeung, "Effects of approach to learning and selfperceived overall competence on academic performance of university students," Learn. Individ. Differ., 2015.

[11] P. Katowa-Mukwato and S. Banda, "Selfperceived versus objectively measured competence in performing clinical practical procedures by final year medical students," Int. J. Med. Educ., vol. 7, pp. 122-129, 2016.

[12] D. O’Doherty, M. Dromey, J. Lougheed, A. Hannigan, J. Last, and D. McGrath, "Barriers and solutions to online learning in medical education - an integrative review Diane," $B M C$ Med. Educ., vol. 18, no. 130, 2018.

[13] R. E. Baticulon et al., "Barriers to online learning in the time of COVID-19: A national survey of medical students in the Philippines," Med. Sci. Educ., 2021.

[14] S. Dost, A. Hossain, M. Shehab, A. Abdelwahed, and L. Al-Nusair, "Perceptions of medical students towards online teaching during the COVID-19 pandemic: A national crosssectional survey of 2721 UK medical students," BMJ Open, vol. 10, no. 11, pp. 1-10, 2020.

[15] Kemenkes RI, Petunjuk Teknis Pelayanan Puskesmas Pada Masa Pandemi Covid-19. 2020.

[16] M. Arnani, "IDI: Kematian Tenaga Medis Indonesia akibat Covid-19 Tertinggi di Asia, Tercatat 647 Meninggal," Kompas.com, 28-Jan2021.

[17] M. Vizheh, M. Qorbani, S. M. Arzaghi, S. Muhidin, Z. Javanmard, and M. Esmaeili, "The mental health of healthcare workers in the COVID-19 pandemic: A systematic review," $J$. Diabetes Metab. Disord., vol. 19, no. 2, pp. 1967-1978, 2020.

[18] N. Salari et al., "The prevalence of stress, anxiety and depression within front-line healthcare workers caring for COVID-19 patients: a systematic review and metaregression," Hum. Resour. Health, vol. 18, no. 1, pp. 1-14, 2020.
[19] K. Samarasekara, "Masking' emotions: Doctorpatient communication in the era of COVID19," Postgrad. Med. J., vol. 0, no. 0, p. 2020, 2020.

[20] S. L. Davey, B. J. Lee, T. Robbins, H. Randeva, and C. D. Thake, "Heat stress and PPE during COVID-19: impact on healthcare workers' performance, safety and well-being in NHS settings," J. Hosp. Infect., vol. 108, pp. 185$188,2021$.

[21] J. F. Ha and N. Longnecker, "Doctor-patient communication: A review," Ochsner J., vol. 10, no. 1, pp. 38-43, 2010. 